\title{
Phospholipase and Esterase Production by Clinical Strains of Fonsecaea pedrosoi and Their Interactions with Epithelial Cells
}

\author{
Vanila Faber Palmeira • Lucimar Ferreira Kneipp • \\ Celuta Sales Alviano · André Luis Souza dos Santos
}

Received: 21 September 2009/Accepted: 14 February 2010/Published online: 1 March 2010

(C) Springer Science+Business Media B.V. 2010

\begin{abstract}
Fonsecaea pedrosoi is the major etiologic agent of chromoblastomycosis. The virulence of $F$. pedrosoi is a meagerly explored phenomenon. The ability to interact with host cells and the production of hydrolytic enzymes are thought to be important virulence mechanisms of fungal pathogens. Here, we measured the production of two distinct lipolytic enzymes, phospholipase and esterase, by three clinical strains of $F$. pedrosoi isolated from chromoblastomycosis lesions, as well as their capabilities to interact with epithelial cells. All the strains were excellent esterase producers, generating elevated hydrolytic halos after 5 days of growth. Conversely, phospholipase activity was detected only after 10 days, except for the most recent strain of F. pedrosoi (Magé) in which measurable phospholipase activity was detected on day 5 . The ability to interact with epithelial cells was also investigated. Regarding the adhesion capability, an indirect
\end{abstract}

V. F. Palmeira - C. S. Alviano - A. L. S. dos Santos ( $\square)$ Departamento de Microbiologia Geral, Instituto de Microbiologia Prof. Paulo de Góes (IMPPG), Centro de Ciências da Saúde (CCS), Bloco I, Universidade Federal do Rio de Janeiro (UFRJ), Ilha do Fundão, Rio de Janeiro, RJ 21941-902, Brazil

e-mail: andre@micro.ufrj.br

L. F. Kneipp

Laboratório de Taxonomia, Bioquímica e Bioprospecção de Fungos, Instituto Oswaldo Cruz - Fundação Oswaldo Cruz, Av. Brasil, 4365-Manguinhos, Rio de Janeiro, RJ 21045-900, Brazil connection was observed in relation to the adaptation time of each strain in axenic culture, in which Magé strain showed the best adhesion ability followed by LDI 11428 and 5VPL strains. Both 5VPL and Magé strains were also detected inside the epithelial cells, while the LDI 11428 strain was rarely detected in cytoplasmatic vacuolar compartments. Moreover, these $F$. pedrosoi strains were able to cause injury in epithelial cells.

Keywords Fonsecaea pedrosoi .

Phospholipase · Esterase · Differentiation ·

Cellular interaction $\cdot$ Clinical strains

\section{Introduction}

Chromoblastomycosis is a human chronic subcutaneous infection, beginning after traumatic implantation of mycelial fragments or conidial cells directly into the tissue, caused by several dematiaceous fungi that are found in soil and in decomposing plant matter [1,2]. Inside the host, infectious propagules adhere to epithelial cells and differentiate into sclerotic forms, which effectively resist destruction by the host effector cells and allow the establishment of chronic disease [reviewed in 3]. Chromoblastomycosis is most frequently observed in tropical and/or subtropical locations, with particularly high incidence rates in Brazil $[4,5]$ and Japan [6, 7]. Fonsecaea pedrosoi is the most 
frequent etiologic agent of chromoblastomycosis in tropical regions. Clinically, chromoblastomycosis is characterized by the slow development of polymorphic skin lesions (nodules, verrucas, tumors, plaques and scar tissue) [1-3].

The virulence attributes expressed by $F$. pedrosoi, which enhance the infective process in chromoblastomycosis, are unknown; however, for the establishment of this infection it is necessary that the fungi adhere, colonize and penetrate into the skin, promoting tissue invasion by digesting or destroying cell membranes and by degrading host surface molecules and/or extracellular matrix components [reviewed in 3]. We have hypothesized that in F. pedrosoi the cell/ tissue invasion might occur by enzymatic digestion, through secretion of proteases and lipases as formerly proposed for other fungal pathogens.

Concerning proteolytic enzymes, our research group demonstrated that both conidial and mycelial forms of $F$. pedrosoi were capable of releasing aspartyl-type proteases into the extracellular environment that hydrolyzed several proteinaceous substrates including serum proteins (albumin, immunoglobulin G and fibrinogen) and extracellular matrix components (fibronectin, laminin and type I collagen), which could help the fungus to disseminate inside the human body [8-10]. In contrast, very little is known about lipase production in $F$. pedrosoi $[11,12]$. Recently, using infrared spectroscopy analysis, which has been used as robust tool in the characterization, classification and identification of microorganisms, Corbellini et al. [12] described suitable results in the quantification of extracellular lipase activity, showing a significant linkage to the biomass production in vitro by some chromoblastomycosis agents, including $F$. pedrosoi.

Phospholipases in general catalyze the hydrolysis of phospholipids, which are major components of all cell membranes, thereby also facilitating fungal invasion [13]. Esterase (or monoacylglycerol lipase) is an enzyme that hydrolyzes monoacylglycerol with a long-chain fatty acid $\left(C_{12}\right.$ or more) [14]. The role of lipases in fungi capable of causing cutaneous and subcutaneous mycoses is probably to hydrolyze fats in the subcutis and the fatty acid residues used as a nutrient source by the invading fungus. In the present study, we have analyzed the production of phospholipase and esterase by three distinct clinical strains of $F$. pedrosoi, as well as their capabilities to interact (adhesion and endocytosis) with epithelial cells.

\section{Materials and Methods}

Microorganisms and Growth Conditions

This study was conducted using three pathogenic strains of Fonsecaea pedrosoi isolated from human patients with chromoblastomycosis and currently studied in our laboratory to demonstrate possible biochemical markers that help the fungus to establish and overpass the host response. In this context, the 5VPL strain has been passed over 30 years only in axenic culture medium, which correspond to more than 600 passages in vitro, while LDI 11428 (6 years, $\sim 50$ passages) and Magé (2 years, $\sim 10$ passages) strains were more recently obtained.

Stock cultures were maintained on Sabouraud dextrose agar under mineral oil and kept at $4{ }^{\circ} \mathrm{C}$. Transfers were made at 6 -month intervals. For conidium formation, cultures were incubated for 5 days under constant agitation $(200 \mathrm{rpm})$ at room temperature in a $250-\mathrm{mL}$ Erlenmeyer flask containing $100 \mathrm{ml}$ of Czapek-Dox chemically defined medium containing $\left(\mathrm{g} \mathrm{l}^{-1}\right)$ : sucrose, $30 ; \mathrm{NaNO}_{3}, 2 ; \mathrm{K}_{2} \mathrm{HPO}_{4}, 1 ; \mathrm{MgSO}_{4} \cdot 7 \mathrm{H}_{2} \mathrm{O}, 0.5 ; \mathrm{KCl}, 0.5$; $\mathrm{FeSO}_{4} \cdot 7 \mathrm{H}_{2} \mathrm{O}, 0.01$; pH 5.5 [8]. Cultures were centrifuged at $4,000 \mathrm{~g}$ for $10 \mathrm{~min}$ at $4^{\circ} \mathrm{C}$, and the cells were washed three times in $1 \mathrm{ml}$ phosphate-buffered saline (PBS; $150 \mathrm{mM} \mathrm{NaCl}, 20 \mathrm{mM}$ phosphate buffer, $\mathrm{pH}$ 7.2). Growth was estimated by counting the conidial cells in a Neubauer chamber.

\section{Mammalian Cells}

Chinese hamster ovary $(\mathrm{CHO})$ cells (kindly provided by Dr Pamela Stanley, Department of Cell Biology, Albert Einstein College of Medicine, New York, USA) were grown at $37^{\circ} \mathrm{C}$ with $5 \% \mathrm{CO}_{2}$ in $25-\mathrm{cm}^{2}$ culture flasks containing DMEM medium (Gibco) supplemented with $10 \%$ fetal bovine serum (FBS) (Gibco). The pH was maintained at 7.2 by the addition of HEPES $\left(3 \mathrm{~g} \mathrm{l}^{-1}\right)$ and $\mathrm{NaHCO}_{3}\left(0.2 \mathrm{~g} \mathrm{l}^{-1}\right)$ to the culture medium. The initial inoculum was $1 \times 10^{5}$ cells $\mathrm{ml}^{-1}$; cultures were subcultured every 2 days and the cells were maintained in exponential growth phase.

Fungus-Host Cells Interaction

Fonsecaea pedrosoi conidial cells were collected by centrifugation at $4,000 \mathrm{~g}$ for $10 \mathrm{~min}$ at $4^{\circ} \mathrm{C}$, washed 
three times in $1 \mathrm{ml}$ PBS, resuspended in DMEM medium and finally inoculated into $\mathrm{CHO}$ cell cultures in order to obtain a final ratio of 10:1 conidia/ epithelial cell. The $\mathrm{CHO}$ cells were incubated with conidia for $1 \mathrm{~h}$ at $37^{\circ} \mathrm{C}$ and then the cultures were washed three times in $1 \mathrm{ml}$ PBS to remove nonadhered conidia, fixed in Bouin's solution and stained with Giemsa. The adhesion and endocytic indexes were determined after randomly counting a minimum of 300 cells on each triplicate coverslip, and experiments were repeated at least three times. The adhesion index was calculated by multiplying the mean number of attached fungi per animal cell by the percentage of infected cells, observed by microscopic examination using an immersion objective in a Zeiss Axioplan 2 microscopy (Germany). Endocytic index was determined by the same way, but using the mean number of ingested fungi $[10,19]$.

Analysis of CHO Cells Damage by the Lactate Dehydrogenase (LDH) Assay

In order to evaluate epithelial cells damage induced by the presence of the fungus, the conidia were collected by centrifugation, washed three times in PBS, resuspended in DMEM medium and then incubated with $\mathrm{CHO}$ cells at $37^{\circ} \mathrm{C}$ for $1 \mathrm{~h}$, at a final ratio of 10 conidia per mammalian cell. After that, the supernatants were collected, centrifuged for removal of conidia and assayed for the presence of LDH, an intracellular-located enzyme, as previously reported [16]. Briefly, LDH activity was analyzed spectrophotometrically in an ELISA reader (Bio-Tek Instruments) by measuring the NADH disappearance rate at $340 \mathrm{~nm}$ during the LDH-catalyzed conversion of pyruvate to lactate. The basal level of LDH activity was considered as the oxidation of NADH by culture supernatants of epithelial cells kept in culture, in the absence of fungi, which was subtracted for each point. The positive control of enzyme activity, taken as $100 \%$, consisted of a CHO lysate obtained using extraction with $0.1 \%$ Triton $\mathrm{X}-100$.

\section{Phospholipase Assay}

Determination of phospholipase production was performed by using egg-yolk agar plates $(1 \mathrm{M} \mathrm{NaCl}$, $5 \mathrm{mM} \mathrm{CaCl} 2$ and $8 \%$ sterile egg-yolk emulsion) according to Price et al. [17]. In this method, egg- yolk digested by phospholipase produces precipitation around fungal colonies. Ten microliters $\left(1 \times 10^{7}\right.$ conidia) of a suspension of each strain was placed in the center of the egg-yolk agar plate $(9-\mathrm{cm}$ diameter Petri dishes). After incubation at $37^{\circ} \mathrm{C}$ for 5,10 and 15 days, the colony diameter (a) and the diameter of colony plus precipitation zone (b) were measured by a digital paquimeter.

\section{Esterase Assay}

The esterase production by $F$. pedrosoi was assayed using the agar medium [18], which was prepared joining $10 \mathrm{~g}$ of peptone, $5 \mathrm{~g}$ of $\mathrm{NaCl}, 0.1 \mathrm{~g}$ of $\mathrm{CaCl}_{2}$, $15 \mathrm{~g}$ of agar, and 1,000 $\mathrm{ml}$ of distilled water, with $\mathrm{pH}$ adjusted to $\mathrm{pH}$ 6.5. After the medium was autoclaved, it was cooled to about $50^{\circ} \mathrm{C}$, and $5 \mathrm{ml}$ of autoclaved Tween 80 (Sigma, St. Louis, Mo) was added. The suspension of $1 \times 10^{7}$ conidia $(10 \mu \mathrm{l})$ was inoculated and plates were incubated at $37^{\circ} \mathrm{C}$ up to 15 days. The colony diameter (a) and the diameter of colony plus precipitation zone (b) were measured by a digital paquimeter.

Enzymatic Score and Statistical Analysis

The phospholipase and esterase activities were expressed as $\mathrm{Pz}$ value $(\mathrm{a} / \mathrm{b})$ as described by Price et al. [17]. According to this definition, low Pz values mean high phospholipase or esterase production and, inversely, high $\mathrm{Pz}$ values indicate low enzymatic production. The $\mathrm{Pz}$ value was scored into four categories: $\mathrm{Pz}$ of 1.0 was evaluated as negative; high $\mathrm{Pz}$ between 0.999 and $0.700(+)$; moderate $\mathrm{Pz}$ between 0.699 and $0.400(++)$; low $\mathrm{Pz}$ between 0.399 and $0.100(+++)$. All the experiments were repeated at least three times and all the systems were performed in triplicate. The data were analyzed statistically using Student's $t$ test. $P$ values of 0.05 or less were considered statistically significant.

\section{Results and Discussion}

First of all, we have compared the association indices of three distinct strains of $F$. pedrosoi after $1 \mathrm{~h}$ of conidia-CHO cells contact (Fig. 1). All the strains were able to interact with $\mathrm{CHO}$ cells, but in different ways. Considering the adhesion capability, an 

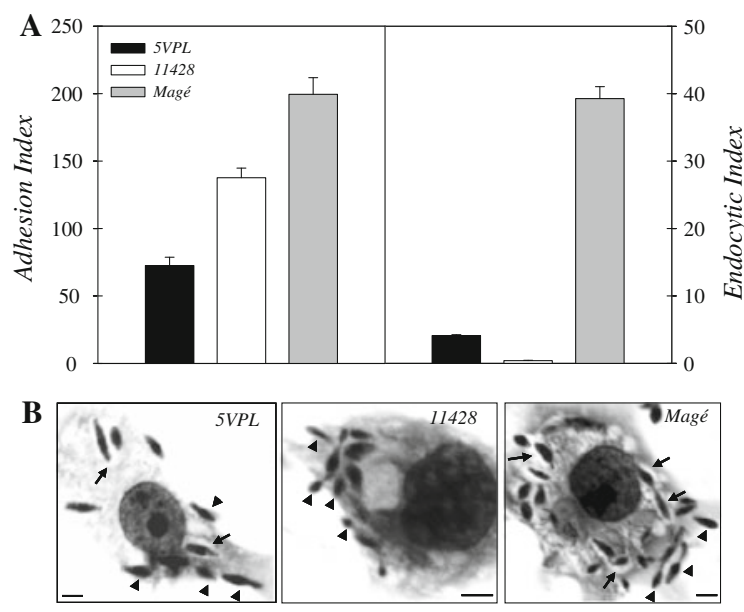

Fig. 1 Interaction profiles between clinical isolates (5VPL, LDI 11428 and Magé strains) of $F$. pedrosoi and epithelial cells $(\mathrm{CHO})$. Adhesion and endocytic indices are shown. The values represent the mean ( \pm standard deviation) of three independent experiments performed in triplicate (A). Representative images of attached (arrowheads) and ingested (arrows) fungi are shown by means of light microscopy analyses. Note that ingested conidia are located within vacuoles (B). Scale bars $10 \mu \mathrm{m}$

indirect association was observed in relation to the adaptation time of each strain in axenic culture, in which the most recent isolate (Magé strain) showed the best adhesion ability followed by LDI 11428 and 5VPL strains (Fig. 1A, B). Both 5VPL and Magé strains were also detected inside the epithelial cells, as judged by the presence of characteristic endocytic vacuoles as previously reported [10, 15], while the LDI 11428 strain was scantily detected in intracellular compartments (Fig. 1A, B).

As is well known, the conidium into hyphae transformation is a hallmark event during the pathogenesis of $F$. pedrosoi [reviewed in 3]. This phenomenon was observed in the two most recent isolates of $F$. pedrosoi studied after $1 \mathrm{~h}$ of contact with epithelial cells in vitro (Fig. 2A). Moreover, the presence of moniliform hyphae was also observed (Fig. 2A). On the other hand, no differentiation was observed in the 5VPL conidial cells after this short interaction period, as described earlier [10, 15]. Interestingly, Magé strain induced an extensive cytoplasmic vacuolization as well as a clear discontinuity of the cytoplasmic membrane in some epithelial cells, suggesting a loss of cellular integrity (Fig. 2A). In order to corroborate these visual findings, we measured the $\mathrm{LDH}$ activity in the

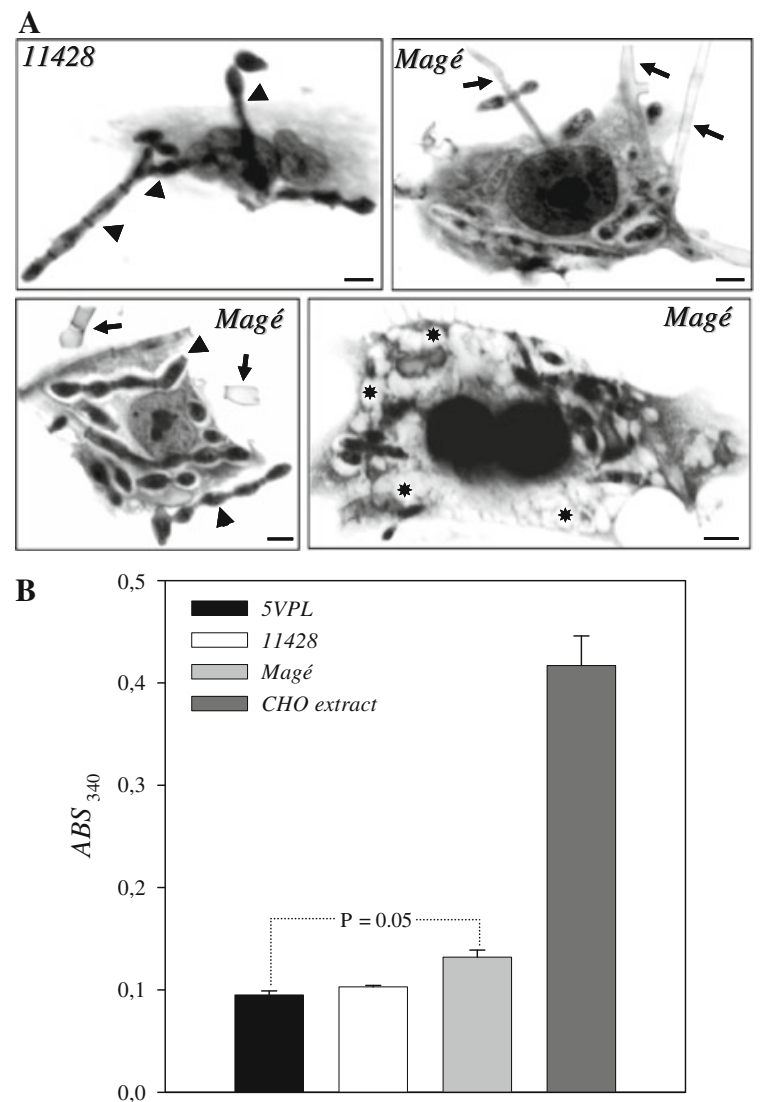

Fig. 2 Analysis of epithelial cells damage by clinical isolates of $F$. pedrosoi. A Morphological transitions after the interaction between $F$. pedrosoi and $\mathrm{CHO}$ cells for $1 \mathrm{~h}$. Note the transformation of conidia into hyphae (arrows) or conidia into moniliform hyphae (arrowheads) in the two most recent $F$. pedrosoi isolates (LDI 11428 and Magé strains). The asterisks show the extensive vacuolization of the cytoplasm. Scale bars: $10 \mu \mathrm{m}$. B Measurement of LDH activity in the supernatants obtained after contact of different clinical isolates of $F$. pedrosoi with $\mathrm{CHO}$ cells. The values represent the mean ( \pm standard deviation) of three independent experiments performed in triplicate. The LDH activity was significantly higher with the Magé strain than the 5VPL strain

supernatants obtained after $1 \mathrm{~h}$ of conidia-CHO cells contact (Fig. 2B). The 5VPL, LDI 11428 and Magé strains were able to cause injury by approximately 23 , 25 and $32 \%$, respectively, in CHO cells (considering the epithelial lysate obtained with Triton X-100 as $100 \%$ of lysis) (Fig. 2B).

Invasion of host cells by fungus entails adhesive capability, penetration and damage of the outer cell envelope. This transmigration process is mediated, most probably, by either physical or enzymatic means or a combination of the two. Phospholipids and 
proteins represent the major components of the host cell membrane. Therefore, enzymes capable of hydrolyzing these components, such as lipases (especially phospholipases and esterases) and proteases, are likely to be involved in the membrane disruption processes that occur during host cell invasion [13].

Phospholipases are ubiquitous enzymes involved in such diverse processes as membrane homeostasis, nutrient acquisition and generation of bioactive molecules. Some phospholipases play a role in microbial pathogenesis and virulence in fungi, as fungi interaction with each other, other microorganisms and their mammalian host [13]. By cleaving phospholipids, phospholipases destabilize the membrane and cell lysis results. Evidence implicating phospholipases in host cell penetration, injury and lysis by fungi has been reported for Candida albicans [19], Cryptococcus neoformans [20] and Aspergillus fumigatus [21]. Consequently, phospholipases have been included among the virulence factors that damage host cells. Herein, we also evaluated the production of phospholipase and esterase activities during $F$. pedrosoi growth up to 15 days in vitro.

Regarding phospholipase activity, only Magé strain showed detectable activity on day 5 of growth (Fig. 3). The phospholipase activity was best detected after 15 days showing moderate values of $\mathrm{Pz}$ ranging from 0.65 to 0.55 . This simple and rapid assay to detect phospholipase activity by measurement of the zone of precipitation around colonies on egg-yolk agar has been largely employed [17]. Furthermore, Chen et al. [20] demonstrated that phospholipase production in 50 clinical and environmental isolates of $C$. neoformans by this technique possessed a straight correlation between phospholipase activity and virulence in mice. Barrett-Bee et al. [22] correlated phospholipase production by $C$. albicans with adherence to buccal epithelial cells. Furthermore, it was observed in a murine model of candidiasis that mortality was increased in mice infected with isolates producing the highest phospholipase activity $[19,22]$. In our study, we cannot correlate the phospholipase production and interaction with $\mathrm{CHO}$ cells by egg-yolk agar plate assay, because of the small sample size. Although the plate method is the traditional screening method for phospholipase activity of Candida species and other fungi such as $C$. neoformans, this assay may not be suitable for the screening of fungal isolates that

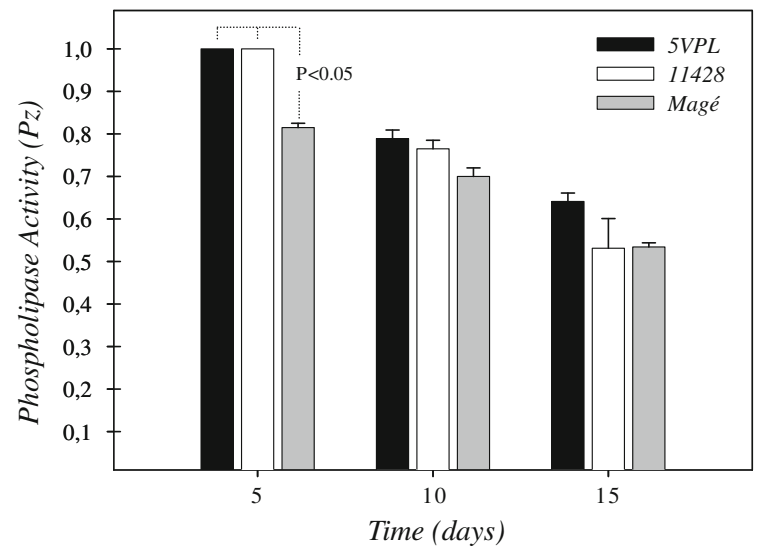

Fig. 3 Phospholipase production by clinical isolates of $F$. pedrosoi by using egg-yolk agar plates. Conidial suspensions (containing $1 \times 10^{7}$ cells) of each strain (5VPL, LDI 11428 and Magé strains) were placed in the center of the egg-yolk agar plate and incubated at $37^{\circ} \mathrm{C}$ for 5,10 and 15 days. The phospholipase activity was expressed as $\mathrm{Pz}$, and the values represent the mean ( \pm standard deviation) of three independent experiments performed in triplicate

produce low levels of phospholipase [13]. More sensitive methods such as radiometric and colorimetric assays are advised to be used particularly in poorly phospholipase-producing strains.

Previous studies have used Tween 80 opacity test for detection of lipolytic activity among various bacteria and fungi. This test has also been reported to aid identification of dermatophytes and Candida [2325]. The hydrolysis of the Tween compound is mediated by the lipolytic enzymes. Subsequent to cleavage of ester bonds, the released fatty acids bind with the calcium ions incorporated in the medium and form insoluble calcium complexes. These complexes result in the characteristic precipitation halo seen around the colony. Production of esterase activity was very well observed even on day 5 of incubation at $37^{\circ} \mathrm{C}$ with Pz ranging between 0.520 and 0.480 (Fig. 4). The esterase activity increased on day 10 of incubation. In addition, a pronounced and significant $(P<0.05)$ increase in the esterase activity was detected in the three strains at day 15 with low Pz values in the range of 0.300 (Fig. 4). Similarly as previously described in $C$. albicans [26], a distinctive pattern of double halo of precipitation was produced by all $F$. pedrosoi strains (data not shown). In the course of this manuscript preparation, Corbellini et al. [12] demonstrated that four different strains of $F$. pedrosoi were able to produce lipase activity after 14 days of in vitro growth, 


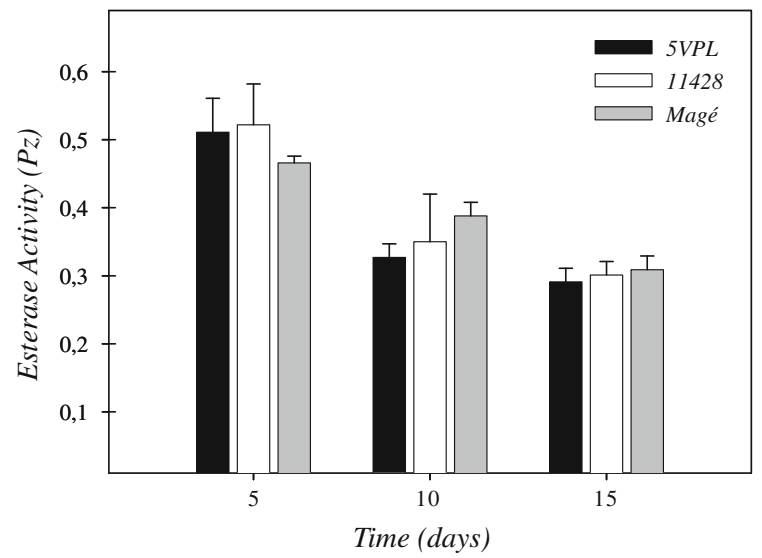

Fig. 4 Esterase production by clinical isolates of $F$. pedrosoi by using Tween 80 opacity test. Conidial suspensions (containing $1 \times 10^{7}$ cells) of each strain (5VPL, LDI 11428 and Magé strains) were placed in the center of the Tween 80 agar plate and incubated at $37^{\circ} \mathrm{C}$ for 5,10 and 15 days. The esterase activity was expressed as $\mathrm{Pz}$, and the values represent the mean ( \pm standard deviation) of three independent experiments performed in triplicate

using $p$-nitrophenyl palmitate as the substrate. Curiously, two of those strains revealed a decrease in the enzymatic activity at 21 days, while other two strains presented an increase in their lipase activity [12].

The virulence of $F$. pedrosoi is a mutifactorial property dependent on many different virulence properties as adhesion to the host cells, formation of hyphae and probably the production of hydrolytic enzymes such as proteases and lipases. In this context, we recently reported that these three strains of $F$. pedrosoi produced different amounts of extracellular aspartyl-type proteases [9, 10]. Interestingly, the $F$. pedrosoi Magé strain produced higher levels of extracellular proteolytic activity when compared with the 5VPL and LDI 11428 strains, suggesting that the production of secreted aspartyl-type proteases may be stimulated by interaction with the host $[9,10]$. A similar study reported the augmentation of the ectophosphatase activity expressed on the cell wall of a recent isolate when compared with a laboratoryadapted strain in F. pedrosoi [27].

The present work reported the production of phospholipase and esterase in different clinical isolates of $F$. pedrosoi as well as their distinct capabilities to interact with epithelial cells. In this sense, conidial cells obtained from recent isolates of $F$. pedrosoi were able to quickly differentiate into hyphae during the contact with mammalian cells, a crucial step during the $F$. pedrosoi life cycle. Furthermore, the three distinct strains of $F$. pedrosoi produced both phospholipase and esterase. Bearing in mind a parallel with other human fungal pathogens, phospholipase and esterase activity in F. pedrosoi may contribute for adhesion, penetration and nutrition in host, during the course of chromoblastomycosis. However, some peculiarities are observed in these three distinct isolates of $F$. pedrosoi in respect to their abilities in promoting damage of epithelial cells. For instance, despite of the best adhesion and internalization of $F$. pedrosoi Mage strain, the capacity to induce epithelial cell damage was not so intense when compared with the other two isolates. We would like to infer that other molecules may be involved in the virulence of this Mage strain, for example the pigment melanin which protects the fungus against microbicidal agents produced by the host cells. In this context, we are conducting a study in order to measure melanin production as well as other potential virulence attributes linked with the ability of $F$. pedrosoi cells in subverting the host cell response. In the same way, the LDI 11428 isolate was capable of inducing cellular injury even without internalization by $\mathrm{CHO}$ cells. We can hypothesize that only the contact between fungi and $\mathrm{CHO}$ can induce cellular damage, probably due to secretion of hydrolytic enzymes, as described herein and in a previous work [10]. These enzymes, acting in cooperation, may destroy lipids and proteins at the surface, disestablishing the plasma membrane homeostasis and leading to $\mathrm{CHO}$ cell death. Additionally, the LDI 11428 strain is also able to rapidly induce conidia into hyphae transformation, an essential step used by different fungi, including $F$. pedrosoi [3], to escape from host response. Consequently, future studies are necessary for substantiating the potential role of lipolytic enzymes in pathogenic process of $F$. pedrosoi. In this sense, the results presented herein open several possibilities, for example, the purification of theses enzymes for better biochemical characterization of their activities and functional relevance of these lipases on both $F$. pedrosoi physiological processes as well as during different steps of the fungal-host relationship.

Acknowledgments This study was supported by the Brazilian agencies: MCT/CNPq, CEPG/UFRJ, FAPERJ, FUJB and CAPES. We wish to thank Igor Tannuri Bandrão for the useful critical English review as well as for the valuable suggestions on the manuscript. 


\section{References}

1. Kwon-Chung KJ, Bennett JE. Chromoblastomycosis. In: Cann C, Hunsberger S, editors. Medical Mycology. Philadelphia: Lea and Febiger Inc.; 1992. p. 337-55.

2. Brandt ME, Warnock DW. Epidemiology, clinical manifestations, and therapy of infection caused by dematiaceous fungi. J Chemother. 2003;15:36-47.

3. Santos ALS, Palmeira VF, Rozental S, Kneipp LF, Nimrichter L, Alviano DS, et al. Biology and pathogenesis of Fonsecaea pedrosoi, the major etiologic agent of chromoblastomycosis. FEMS Microbiol Rev. 2007;31:570-91.

4. Silva JP, De Souza W, Rozental S. Chromoblastomycosis: a retrospective study of 325 cases on Amazonic region (Brazil). Mycophatologia. 1999;143:171-5.

5. Minotto R, Bernardi CD, Mallmann LF, Edelweiss MI, Scroferneker ML. Chromoblastomycosis: a review of 100 cases in the state of Rio Grande do Sul, Brazil. J Am Acad Dermatol. 2001;44:585-92.

6. Kondo M, Hiruma M, Nishioka Y, Mayuzumi N, Mochida $\mathrm{K}$, Ikeda $\mathrm{S}$, et al. A case of chromomycosis caused by Fonsecaea pedrosoi and a review of reported cases of dematiaceous fungal infection in Japan. Mycoses. 2005;48:221-5.

7. Richard-Blum S, Hartmann DJ, Esterre P. Monitoring of extracellular matrix metabolism and cross-linking in tissue, serum and urine of patients with chromoblastomycosis, a chronic skin fibrosis. Eur J Clin Invest. 1998;28:748-54.

8. Palmeira VF, Kneipp LF, Alviano CS, Santos ALS. The major chromoblastomycosis fungal pathogen Fonsecaea pedrosoi extracellularly releases proteolytic enzymes whose expression is modulated by culture medium composition: implications on the fungal development and cleavage of key's host structures. FEMS Immunol Med Microbiol. 2006;46:21-9.

9. Palmeira VF, Kneipp LF, Alviano CS, Santos ALS. Secretory aspartyl peptidase from mycelia of Fonsecaea pedrosoi: effect of HIV peptidase inhibitors. Res Microbiol. 2006;157:819-26.

10. Palmeira VF, Kneipp LF, Rozental S, Alviano CS, Santos ALS. Beneficial effects of HIV peptidase inhibitors on Fonsecaea pedrosoi: promising compounds to arrest key fungal biological processes and virulence. PLoS ONE. 2008;3:e3382.

11. Okeke CN, Gugnani HC. Lipases of Fonsecaea pedrosoi and Phialophora verrucosa. Antonie van Leeuwenhoek. 1989;55:313-24.

12. Corbellini VA, Scroferneker ML, Carissimi M, Da Costa JM, Ferrão MF. Lipolytic activity of chromoblastomycosis agents measured by infrared spectroscopy and chemometric methods. Med Mycol. 2009;47:63-9.
13. Ghannoun MA. Potential role of phospholipase in virulence and fungal pathogenesis. Clin Microbiol Rev. 2000;13:122-43.

14. Aktas E, Yigit N, Ayyldiz A. Esterase activity in various Candida species. J Int Med Res. 2002;30:322-4.

15. Limongi CL, Rozental S, Alviano CS, De Souza W. The influence of surface carbohydrates on the interaction of Fonsecaea pedrosoi with Chinese hamster ovary glycosylation mutant cells. Mycophatologia. 1997;138:127-35.

16. Wroblewski F, Ladue JS. Lactic dehydrogenase activity in blood. Proc Soc Exp Biol Med. 1955;90:210-3.

17. Price MF, Wilkinson ID, Gentry LO. Plate method for detection of phospholipase activity in Candida albicans. Sabouraudia. 1982;15:179-85.

18. Schoofs A, Odds FC, Colebunders R, Leven M, Goussens $\mathrm{H}$. Use of specialized isolation media for recognition and identification of Candida dubliniensis isolates from HIVinfected patients. Eur J Clin Microbiol Infect Dis. 1997; 16:296-300.

19. Ibrahim AS, Mirbod F, Filler SG, Banno Y, Cole GT, Kitajima Y, et al. Evidence implicating phospholipase as a virulence factor of Candida albicans. Infect Immun. 1995;63:1993-8.

20. Chen SC, Wright LC, Golding JC, Sorrell TC. Purification characterization of secretory phospholipase B lysophospholipase and lysophospholipase/transacylase from a virulent strain of the pathogenic fungus Cryptococcus neoformans. Biochem J. 2000;347:431-9.

21. Shen DK, Noodeh AD, Kazemi A, Grillot R, Robson G, Brugère JF. Characterisation and expression of phospholipases B from the opportunistic fungus Aspergillus fumigatus. FEMS Microbiol Lett. 2004;239:87-93.

22. Barrett-Bee K, Hayes Y, Wilson RG, Ryley JF. A comparison of phospholipase activity, cellular adherence and pathogenicity of yeasts. J Gen Microbiol. 1985;131:121721.

23. Rudek W. Esterase activity in Candida species. J Clin Microbiol. 1978;8:756-69.

24. Slifkin M, Cumbie R. Evaluation of the Tween 80 opacity test in the identification of dermatophytes. Med Microbiol Lett. 1996;5:401-7.

25. Slifkin M. Tween 80 opacity test responses of various Candida species. J Clin Microbiol. 2000;38:4626-8.

26. Kumar CP, Menon T, Sundararajan T, Nalini S, Thirunarayan MA, Rajasekaran S, et al. Esterase activity of Candida species isolated from immunocompromised hosts. Rev Iberoam Micol. 2006;23:101-3.

27. Kneipp LF, Palmeira VF, Pinheiro AAS, Alviano CS, Rozental S, Travassos LR, et al. Phosphatase activity on the cell wall of Fonsecaea pedrosoi. Med Mycol. 2003;41:469-77. 